Abstracta Iranica

Revue bibliographique pour le domaine irano-aryen

Volume 32-33 | 2013

Comptes rendus des publications de 2009-2010

\title{
Ziony Zevit. Is there an Archaeological Case for Phantom Settlements in the Persian Period?
}

\section{Astrid Nunn}

\section{(2) OpenEdition}

1 Journals

Édition électronique

URL : http://journals.openedition.org/abstractairanica/40447

DOI : $10.4000 /$ abstractairanica. 40447

ISSN : 1961-960X

\section{Éditeur :}

CNRS (UMR 7528 Mondes iraniens et indiens), Éditions de l'IFRI

\section{Édition imprimée}

Date de publication : 1 décembre 2013

ISSN : 0240-8910

\section{Référence électronique}

Astrid Nunn, "Ziony Zevit. Is there an Archaeological Case for Phantom Settlements in the Persian Period? », Abstracta Iranica [En ligne], Volume 32-33 | 2013, document 134, mis en ligne le 01 juillet 2016, consulté le 27 septembre 2020. URL : http://journals.openedition.org/abstractairanica/40447 ; DOI : https://doi.org/10.4000/abstractairanica.40447

Ce document a été généré automatiquement le 27 septembre 2020.

Tous droits réservés 


\title{
Ziony Zevit. Is there an Archaeological Case for Phantom Settlements in the Persian Period?
}

\author{
Astrid Nunn
}

\section{RÉFÉRENCE}

Ziony Zevit. «Is there an Archaeological Case for Phantom Settlements in the Persian Period?». PEQ 141/2, 2009, p. 124-137.

1 Cet article se réfère à celui de I. Finkelstein (cf. Abs. Ir. 31, 2008, c.r. $n^{\circ} 44$ ) selon lequel la liste des Rapatriés ne reflète pas une réalité achéménide, puisque des sites importants de cette époque manquent, mais celle plus tardive de l'époque hasmonéenne. L'A. de ce nouvel article argumente en la faveur de l'historicité du texte biblique. La période perse est encore difficile à reconnaître en Judée. Certaines caractéristiques de la céramique achéménide apparaissent en fait déjà à l'époque du Fer, d'autres, au contraire, plusieurs décennies après la conquête perse. Ceci rend confuse, selon l'A., l'utilisation du terme de "Période perse". Sa conclusion : il faut étudier cette liste dans le cadre plus large de la politique de Cyrus tout en utilisant des textes non bibliques.

\section{AUTEURS}

ASTRID NUNN

Université de Munich 